\title{
Compound Design for Continuously Cast Concrete to Underlie an Extensive Ice Layer in the 13th National Winter Games Venues
}

\author{
Liu Jun, Zhang Ping, Wang Qin, Li Kai, Chen Xu*, Bai Guoqiang \\ China West Construction Group Xinjiang Co., Ltd, Urumqi, China \\ Email address: \\ 1572945039@qq.com (Liu Jun),237930@126.com (Zhang Ping),2324313918@qq.com (Wang Qin), 814026442@qq.com (Li Kai), \\ 645072007@qq.com (Chen Xu),420771478@qq.com (Bai Guoqiang) \\ ${ }^{*}$ Corresponding author
}

To cite this article:

Liu Jun, Zhang Ping, Wang Qin, Li Kai, Chen Xu, Bai Guoqiang. Compound Design for Continuously Cast Concrete to Underlie an Extensive Ice Layer in the 13th National Winter Games Venues. Advances in Materials. Vol. 7, No. 3, 2018, pp. 82-88. doi: 10.11648/j.am.20180703.15

Received: July 5, 2018; Accepted: August 21, 2018; Published: September 26, 2018

\begin{abstract}
This paper details the design process and testing procedure used to create frost-resistant concrete for this engineering project, which involved considering properties such as tendency to shrinkage and durability. Through the examination of performance indices, it is shown that the designed concrete mix met the requirements of the design and of construction through continuous casting, specifically C40F250 concrete with a low shrinkage rate, good performance under freeze-thaw conditions, and no cracking under the pressure of an extensive layer of ice.
\end{abstract}

Keywords: Shrinkage Characteristics, Freeze-Thaw Performance, Ice Pressure, Continuous Pouring, Concrete

\section{Introduction}

The ice sports center for the 13th China National Winter Games was located in Shui Xi-gou township, Urumqi county. The project comprised a speed skating hall, an ice hockey hall, a curling hall, a media center and organizing committee headquarters, a restaurant and dormitory, and a power center. The total construction area of the curling hall was approximately $7,472.15 \mathrm{~m}^{2}$, and the building was $21.7 \mathrm{~m}$ high. It included a basement for equipment storage and offices and practice areas for the athletes on the first to third floors. The speed skating hall was classed a sports building, with 3015 seats, a floor area of $28,790 \mathrm{~m}^{2}$, and a total height of $33 \mathrm{~m}$. The ice hockey hall, also classed a sports building, had a total construction area of about $11,549.1 \mathrm{~m}^{2}$, a height of $24.5 \mathrm{~m}$, and three above-ground stories. The project employed German and Austrian experts to devise, through discussion, a special concrete design that would meet the European and national standards for concrete durability and mechanical performance.
On the basis of the design requirements, to ensure the integrity of the tube-confined ice layer and to meet the needs of construction via continuous casting with laser levelling, it was determined whether it was possible to compensate for concrete shrinkage and so ensure the integrity of the concrete without the addition of an expansion agent [1-2]. The concrete, as the primary support for the ice, was placed under the dual action of the weight and low temperature of the ice, which put high demands on the frost resistance and mechanical properties of the concrete. This paper presents the results of finite element analysis and experimental testing of concrete meeting the above-mentioned design requirements.

\section{Materials}

The design requirements stipulated that locally obtained ordinary concrete raw materials, a high-quality gas attractor and high-performance polycarboxylic acid water reducer would be used. They also ruled out the use of an expansion agent. 


\subsection{Cement}

Table 1. Test data for major cement projects.

\begin{tabular}{llllll}
\hline \multirow{2}{*}{ Alkali content/\% } & \multirow{2}{*}{ Chloride ion content $/ \%$} & \multicolumn{2}{l}{ Flexural strength / MPa } & \multicolumn{2}{l}{ Compressive strength / MPa } \\
\cline { 2 - 6 } & & $\mathbf{3 d}$ & $\mathbf{2 8 d}$ & $\mathbf{3 d}$ & $\mathbf{2 8 d}$ \\
\hline 0.69 & 0.02 & 5.9 & 8.6 & 30.1 & 49.8 \\
\hline
\end{tabular}

$\mathrm{P} \cdot \mathrm{O} 42.5$ grade cement was tested according to the GB 175-2007 general Portland cement standard. The testing data for the major projects are shown in Table 1.

\subsection{Fly Ash}

Table 2. Test data for major implementations of fly ash (\%).

\begin{tabular}{llllll}
\hline Fineness & Water content radio & Alkali content & Chloride ion content & Ignition loss & Sulfur trioxide content \\
\hline 17.5 & 97 & 2.01 & 0.02 & 1.6 & 0.7 \\
\hline
\end{tabular}

Grade II fly ash was tested to the GB/T 1596-2005 standard for cement and fly ash in concrete. The testing data for the main projects are shown in Table 2.

\subsection{Fine Aggregate}

Table 3. Test data for major implementations of fine aggregate.

\begin{tabular}{lllll}
\hline Fineness & Silt content $/ \mathbf{\%}$ & Clod content $/ \%$ & Chloride ion content $/ \%$ & Sturdiness \\
\hline 3.5 & 1.9 & 0.4 & 0.01 & 3.0 \\
\hline
\end{tabular}

The coarse sand produced most locally in Xinjiang was adopted and was tested in accordance with the requirements of the JGJ52-2006 standard "Sand, stone quality and inspection methods for Putong concrete." The testing data for the major projects are shown in Table 3.

\subsection{Coarse Aggregate}

Table 4. Test data for major implementations of coarse aggregate.

\begin{tabular}{lllll}
\hline Specification & Silt content $/ \%$ & Clod content $/ \%$ & Crushing value index $/ \%$ & Needle and plate particle content /\% \\
\hline $5 \sim 20$ & 0.3 & 0.1 & 2.0 & 4.0 \\
\hline
\end{tabular}

Gravel produced in Xinjiang with 5-20 mm grading was obtained and tested in accordance with the requirements of JGJ 52-2006. The testing data for the major projects are shown in Table 4.

\subsection{Air-Entraining Agent}

Table 5. Test data for major implementations of air-entraining agent.

\begin{tabular}{|c|c|c|c|c|}
\hline \multirow{2}{*}{ Water-reducing rate $/ \%$} & \multirow{2}{*}{ Air content $/ \%$} & \multirow{2}{*}{ Air content changes in 1 hour $/ \%$} & \multicolumn{2}{|c|}{ Setting time difference / min } \\
\hline & & & Initial setting & Final setting \\
\hline 8.0 & 4.5 & -1.0 & 20 & -60 \\
\hline
\end{tabular}

An air-entraining liquid admixture was used according to GB 8076-2008. The testing data for the major projects are shown in Table 5 .

\subsection{High-Performance Water-Reducing Agent}

Table 6. Test data for major implementations of high-performance water-reducing agent (\%).

\begin{tabular}{llll}
\hline Solid content & Water-reducing rate & total alkali content & Chloride ion content \\
\hline 15.5 & 29.0 & 0.18 & 0.02 \\
\hline
\end{tabular}

Polycarboxylic acid was used as a high-performance water-reducing agent and assessed on the basis of GB8076-2008, the GB/T 8077-2012 testing method for the homogeneity of concrete admixtures, and the GB 50119-2013 technical specification for concrete admixture application. The testing data for the major projects are shown in Table 6 .

\subsection{Synthetic Fiber}

Approximately $19 \mathrm{~mm}$-long short polypropylene fiber was used to improve the early cracking resistance of the concrete [3]. 


\section{Concrete Testing}

\subsection{Principles of Concrete Mix Design}

The concrete in this paper was devised to solve concrete shrinkage, frost resistance and other durability issues, as well as ensuring mechanical performance and suitability for the construction method. The design requirements were that it would meet a control value of concrete slump of 180-220 mm, no more than $30 \mathrm{~mm}$ of slump in $1 \mathrm{~h}$, a gas content of 4.5 $6.5 \%$, and a compressive strength no lower than the design requirements for $\mathrm{C} 40$. All of these were met. Concrete shrinkage mainly results from

Table 7. Concrete mix ratio for $C 40 F 250\left(\mathrm{~kg} / \mathrm{m}^{3}\right)$.

\begin{tabular}{|c|c|c|c|c|c|c|c|c|c|c|}
\hline $\begin{array}{l}\text { Design } \\
\text { indicators }\end{array}$ & Number & Cement & Fly ash & $\begin{array}{l}\text { Mineral } \\
\text { power }\end{array}$ & Sand & 5 20mmStone & Admixtures & $\begin{array}{l}\text { Air-entraining } \\
\text { agent }\end{array}$ & $\begin{array}{l}\text { Synthetic } \\
\text { fiber }\end{array}$ & Water \\
\hline \multirow{2}{*}{$\begin{array}{l}\text { C40 } \\
\text { F250 }\end{array}$} & $1+5$ & 232 & 69 & 85 & 752 & 1127 & 7.72 & 1.16 & 4.32 & 135 \\
\hline & 1 & 270 & 81 & 99 & 708 & 1107 & 9.00 & 1.35 & 4.32 & 135 \\
\hline
\end{tabular}

(Note: Mix " 1 " is the calculated mix ratio, and " $1+5$ " refers to the mix ratio with a $0.05 \%$ increase in the water-cement ratio of $0.05 \%$ and of $1 \%$ in the sand ratio. "1-5" indicates a $0.05 \%$ reduction in the water-cement ratio and $1 \%$ in the sand ratio. The recommended dosage of $2.0 \%$ was used for the polycarboxylic acid high-performance water-reducing agent. The total amount of air-entraining agent was $0.3 \%$ of the total amount of the cement binding materials. The volume fraction of polypropylene fibers was $0.2 \%$, and the density was $0.9 \mathrm{~g} / \mathrm{cm}^{3}$.

The flow rate was the maximum volume of water consumed per $\mathrm{m}^{3}$. dry shrinkage and self-shrinkage [4-5], which are a manifestation of the incorporation of the moisture inside the concrete into the crystal structure of its mineral components. A concrete expansion agent, which contains substances that expand during crystal hydration, is often added to offset the contraction. As the design required that such agents not be added, methods that could prevent shrinkage solely through varying the mixing proportions of the concrete were considered. One is to use a low water/cement ratio to reduce the free water inside the concrete. Another is to include a polycarboxylic acid high-performance water-reducing agent in the mix [6]; this will improve the working performance of the concrete at the same time as improving its mechanical properties. Additionally, controlling the alkali content of the cement will help, as will mixing in a mineral admixture that reduces the early heat of hydration of the concrete and participates in secondary hydration. A further approach is to improve anti-cracking performance by mixing polypropylene synthetic fibers into the concrete. Mixing in an air-entraining agent is also valuable, as it optimizes the internal pore structure and improves the working performance and frost resistance of the concrete while reducing shrinkage cracking [7-8]. The JGJ 55 -- 2011 design rules for the ordinary concrete mix ratio plus production experience of appropriate concrete mix ratios were used to arrive at the specific mix ratio design [9] shown in Table 7.

\subsection{Performance Testing}

Concrete performance was measured on the basis of the GB/T 50080-2002 standard for performance testing ordinary concrete mixtures. The dosage of water-reducing agent and water consumption were adjusted to achieve a match with control index values for concrete slump [10], slump loss, and air content. Selected test results in Table 8 show that these adjustments successfully enabled the three mixing ratios to meet the requirements of the design indicators.

\subsection{Mechanical Testing}

The GB/T 50081-2002 method for testing the mechanical performance of ordinary concrete was applied to $3 \mathrm{~d}, 7 \mathrm{~d}, 14 \mathrm{~d}$, $28 \mathrm{~d}$ and $60 \mathrm{~d}$-old molded specimens to assess changes in strength with age. Selected test results are shown in Table 9.

Table 8. Performance results for concrete.

\begin{tabular}{|c|c|c|c|c|c|c|c|c|c|}
\hline \multirow[b]{2}{*}{$\begin{array}{l}\text { Design } \\
\text { indicators }\end{array}$} & \multirow[b]{2}{*}{ Number } & \multirow[b]{2}{*}{$\begin{array}{l}\text { Actual admixture } \\
\text { content }\end{array}$} & \multirow[b]{2}{*}{$\begin{array}{l}\text { Actual } \\
\text { water }\end{array}$} & \multicolumn{5}{|c|}{ Performance } & \multirow[b]{2}{*}{$\begin{array}{l}\text { Air content } \\
/ \%\end{array}$} \\
\hline & & & & $\begin{array}{l}\text { Slump / } \\
\text { mm }\end{array}$ & $\begin{array}{l}\text { Extension / } \\
\text { mm }\end{array}$ & $\begin{array}{l}\text { 1h slump } \\
\text { loss / mm }\end{array}$ & $\begin{array}{l}\text { Adhesivene } \\
\text { ss }\end{array}$ & $\begin{array}{l}\text { Water } \\
\text { retention }\end{array}$ & \\
\hline \multirow{3}{*}{$\mathrm{C} 40 \mathrm{~F} 250$} & $1+5$ & 2.3 & 127 & 205 & 580 & 170 & fine & fine & 4.8 \\
\hline & 1 & 2.4 & 125 & 210 & 630 & 195 & fine & fine & 5.8 \\
\hline & $1-5$ & 2.5 & 123 & 220 & 670 & 200 & fine & fine & 5.1 \\
\hline
\end{tabular}

Table 9. Test results on the mechanical properties of concrete.

\begin{tabular}{|c|c|c|c|c|c|c|}
\hline \multirow{2}{*}{ Design indicators } & \multirow{2}{*}{ Number } & \multicolumn{5}{|c|}{ Compressive strength / MPa } \\
\hline & & 3d & $7 d$ & 14d & 28d & 60d \\
\hline \multirow{3}{*}{$\mathrm{C} 40 \mathrm{~F} 250$} & $1+5$ & 12.1 & 26.2 & 34.8 & 42.6 & 46.3 \\
\hline & 1 & 16.2 & 31.2 & 38.0 & 49.6 & 54.4 \\
\hline & $1-5$ & 20.1 & 36.5 & 44.4 & 56.2 & 59.6 \\
\hline
\end{tabular}

Figure 1 shows the development curve of compressive strength with age under standard curing conditions for the three water-cement ratios that met the design requirements [7]. 


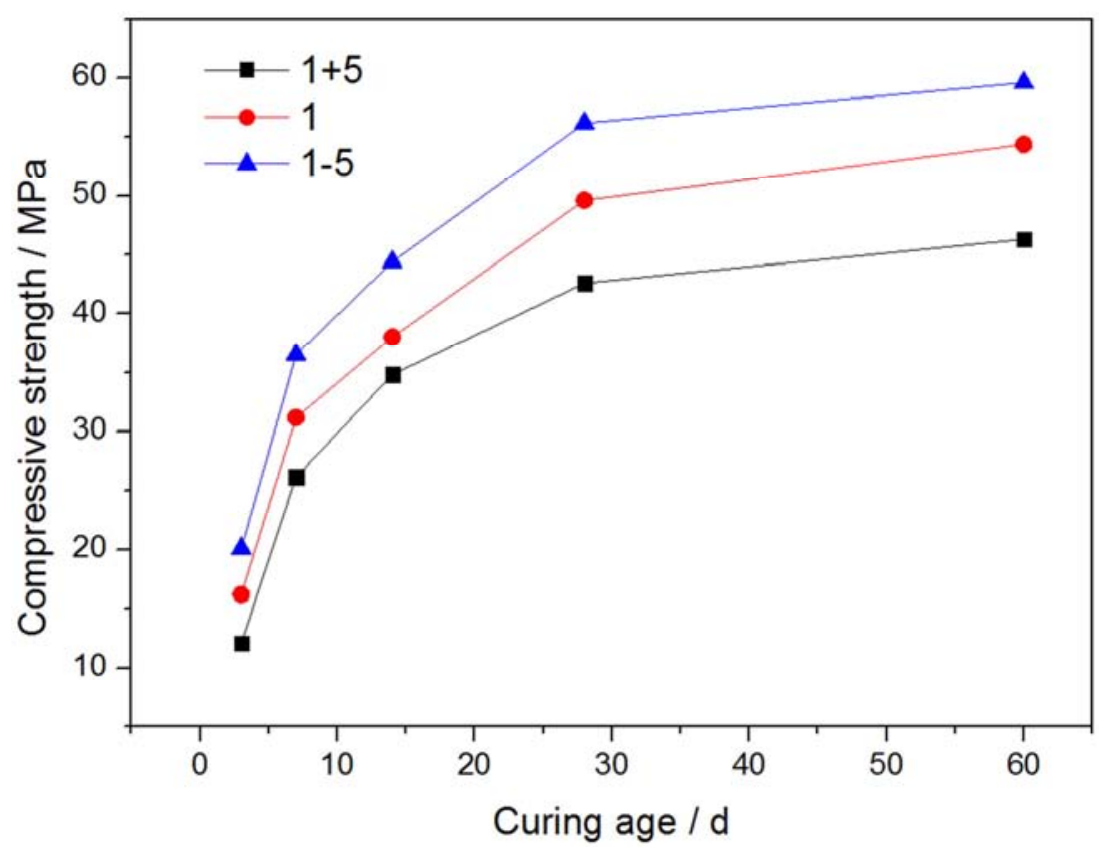

Figure 1. Development of compressive strength with age with standard curing.

Figure 1 shows that the strength development of calculated mix ratio "1" met the requirements for concrete preparation; it also allows the design requirements to be met more economically than with ratio "1-5".

\subsection{Durability Testing}

The engineering design requirements and the characteristics of the construction process meant assessment of the durability of the concrete concentrated on shrinkage performance [11], early crack resistance, and frost resistance. The calculated mix ratio "1", which satisfies the requirements for working performance and mechanical performance, was tested for durability according to the GB/T 50082-2009 standard for testing the long-term performance and durability of ordinary concrete [12].

\subsection{Shrinkage}

A non-contact method was used to determine the free shrinkage deformation of early-age concrete [13]. The deformation measurement instrument used had automatic data collection and processing functionality. The specimen size was a $100 \mathrm{~mm} \times 100 \mathrm{~mm} \times 100 \mathrm{~mm}$ prism. Each test was carried out on three specimens. The test temperature was $(20+2)^{\circ} \mathrm{C}$, and the relative humidity was $(60+5) \%$. The calculated " 1 " blend ratio was used with $8 \%$ external dosage with a UEA-type expansion agent and the addition of polypropylene fiber blend in a ratio designated "2". Comparison was made with an experiment where the mix was not doped with polypropylene fiber or expansive agent ("0"). Testing was conducted at ages of $3 \mathrm{~d}, 7 \mathrm{~d}$, and $14 \mathrm{~d}$. The results are shown in Table 10.

Table 10. Concrete shrinkage data at different curing ages.

\begin{tabular}{lllll}
\hline \multirow{2}{*}{ Number } & \multicolumn{2}{l}{ Shrinkage rate of concrete of various ages /\% } & \multirow{2}{*}{ Descr } \\
\cline { 2 - 4 } & $\mathbf{3 d}$ & $\mathbf{7 d}$ & $\mathbf{1 4 d}$ & no fiber, no swelling agent \\
\hline 0 & 0.0184 & 0.0216 & 0.0279 & with fiber, no swelling agent \\
1 & 0.0102 & 0.0146 & 0.0184 & no fiber, with swelling agent \\
2 & 0.0099 & 0.0135 & 0.0175 & \\
\hline
\end{tabular}

Table 10 shows that the incorporation of fiber reduced the shrinkage rate of the concrete to a certain extent, having an effect that was not far different from the incorporation of an expansion agent. Additionally, good curing conditions could further reduce the early shrinkage of the concrete. It is feasible to design a concrete mix ratio with a low shrinkage rate by using a low water-cement ratio, a mineral admixture that reduces the early heat of hydration, and proper air drainage.

\subsection{Resistance to Cracking}

Early cracking in concrete is mainly caused by plastic shrinkage and settlement shrinkage [14]. This study tested early cracking caused by plastic shrinkage for different mixing ratio designs. A slab was molded in a standard $800 \mathrm{~mm} \times 600 \mathrm{~mm} \times$ $100 \mathrm{~mm}$ plate-type mold with 7 crack inducers at a temperature of $(20+2)^{\circ} \mathrm{C},(60+5) \%$ relative humidity, and a specimen surface wind speed of not less than $5 \mathrm{~m} / \mathrm{s}$. The calculated control parameters of concrete antifreeze performance from the center of Table 11 were applied, and cracks were measured at $(24 \pm 1) \mathrm{h}$ intervals [15]. Figure 2 shows a crack diagram of the design index C40F250 concrete slab. 

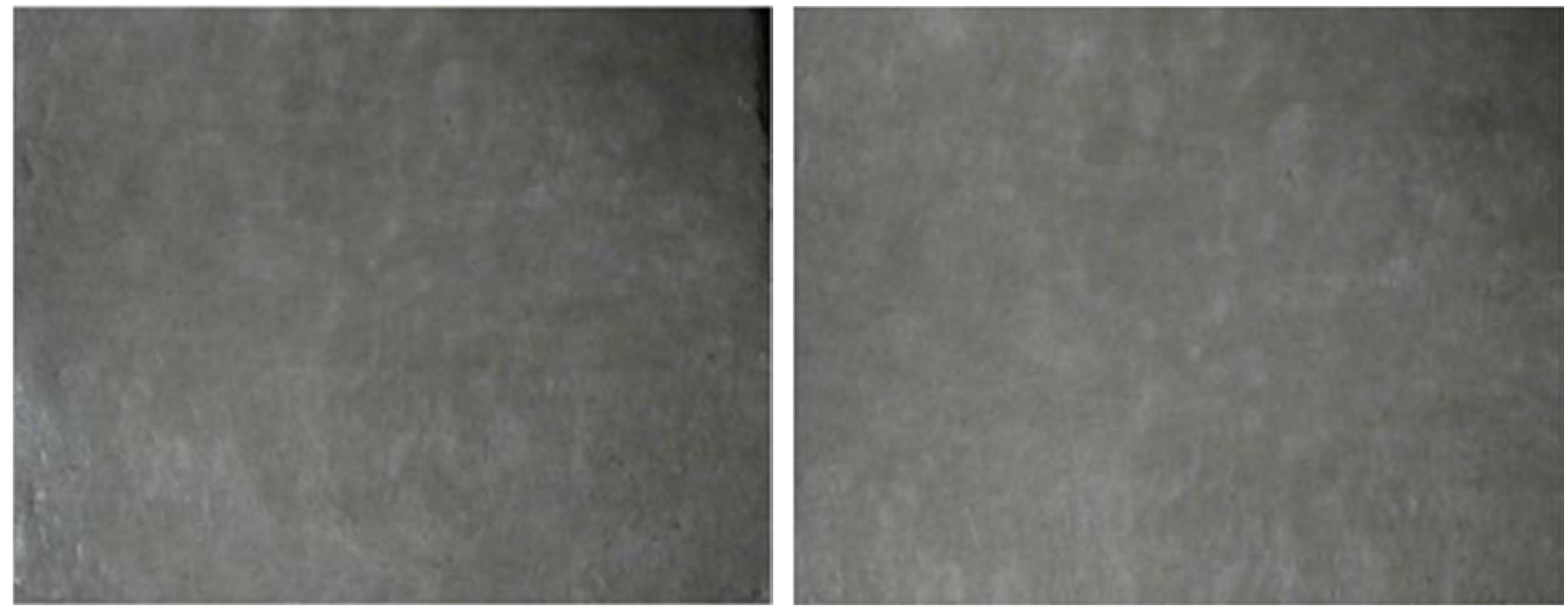

Figure 2. Crack map for a C40F250 high-performance concrete slab.

As shown in Figure 2, the early cracking resistance of the concrete was excellent; no obvious cracks occurred, thus meeting the design requirements.

\subsection{Frost Resistance}

A quick freeze-thaw cycle was adopted to test the number "1" specimen for frost-resistance. It was subjected to 50 cycles to determine the quality and loss modulus, giving the test results in Table 11.

The data in Table 12 show that an appropriate adjustment of the water reducing agent in mix " 1 " allows the frost resistance requirements of the F250 concrete index to be met. It thus meets the design requirements and the $\mathrm{C} 40 \mathrm{~F} 250$ construction technology standard.

Table 11. Concrete frost resistance.

\begin{tabular}{lll}
\hline Cycle-index & Mass loss rate /\% & Relative kinetic modulus $/ \%$ \\
\hline 50 & 0.21 & 97.2 \\
100 & 0.70 & 94.4 \\
150 & 1.06 & 92.2 \\
200 & 1.45 & 90.5 \\
250 & 1.98 & 88.4 \\
300 & 2.35 & 85.7 \\
\hline
\end{tabular}

Table 12. Theoretical concrete mixture ratio for C40F250.

\begin{tabular}{|c|c|c|c|c|c|c|c|c|c|}
\hline Design indicators & Cement & Fly ash & Mineral power & Sand & 5 20mmStone & Admixtures & Air-entraining agent & Synthetic fiber & Water \\
\hline $\mathrm{C} 45 \mathrm{~F} 250$ & 270 & 81 & 99 & 708 & 1107 & 10.80 & 1.35 & 4.32 & 125 \\
\hline
\end{tabular}

\section{Evaluation of the Application of the Concrete Design}

The construction of the venue for the 13th National Winter Games (featuring a speed skating hall, hockey hall, and curling pavilion) adopted a reinforced concrete structure with large-diameter longitudinal embedded PE refrigeration pipes. The project adopted a one-time continuous pour and vibration controlled by automatic laser leveling. There were many requirements for the concrete, such as the properties of the overbar, crack resistance, mechanical performance, and durability (in particular, frost resistance). An appropriate concrete mixture was identified through construction mix proportioning as described in this paper, repeated laboratory tests, and early feasibility analysis, and the concrete pouring work for the three main stadia was completed near the end of 2014. The mechanical properties and antifreeze performance met the design requirements, cracks did not form, and the integrity was excellent. It was approved by the State General Administration of Sports and by the German experts. German and Austrian experts spoke highly of the construction and design, confirming the world-class level of the techniques used.

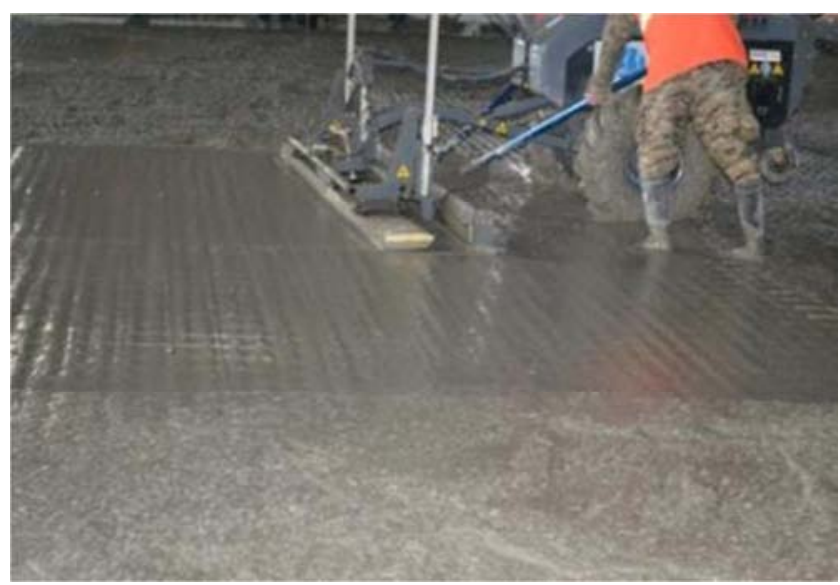




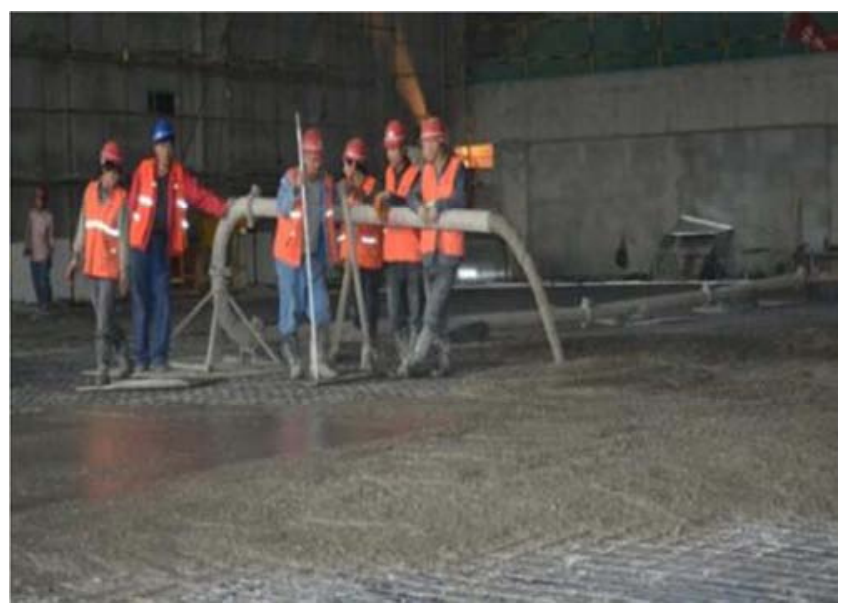

Figure 3. Construction of the ice hockey hall.

The 13th National Winter Games were officially held from the solstice on January 20, 2016 to January 30, 2016. They were approved by the State Council, sponsored by the State General Administration of Sports, and undertaken by the Xinjiang government. This was the first time that this national multi-sport event had been held in this region. The ice in the pavilion was smooth and suffered no crack damage, confirming the exceptionally high standard of the concrete design and construction technology used.
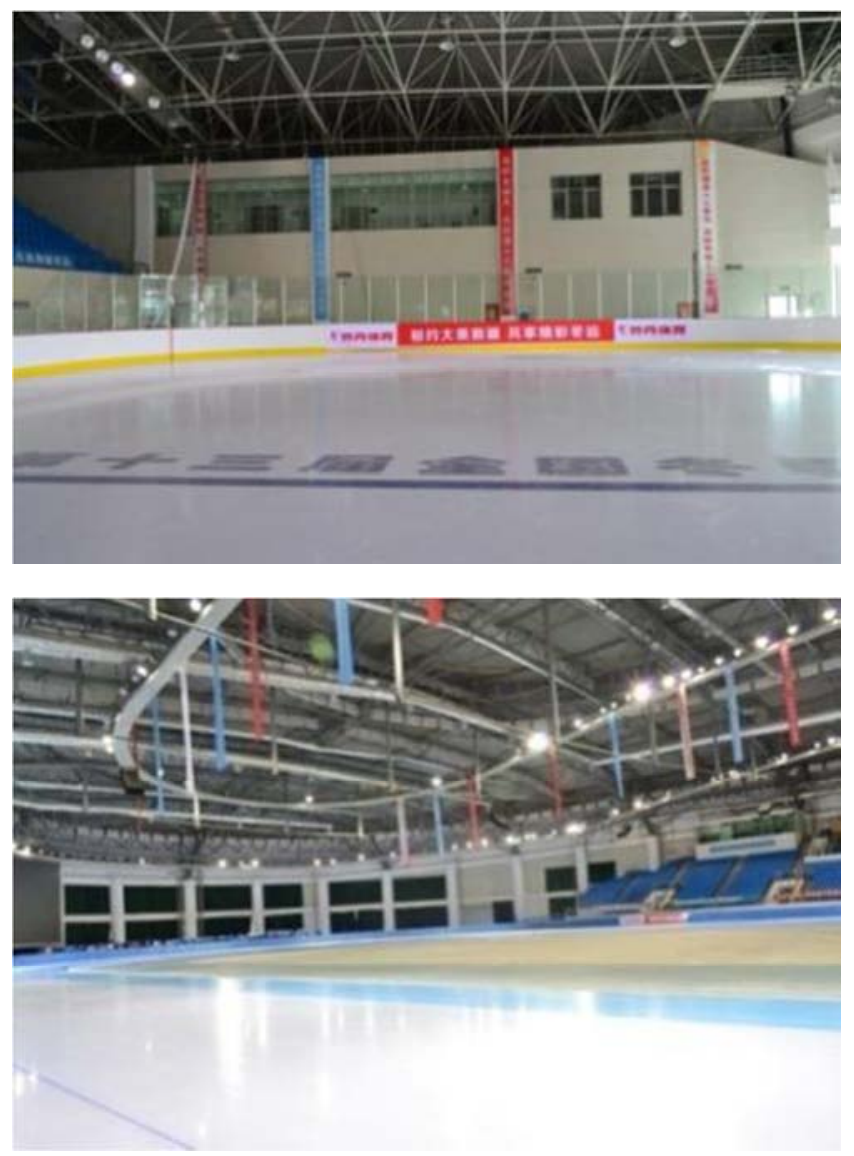

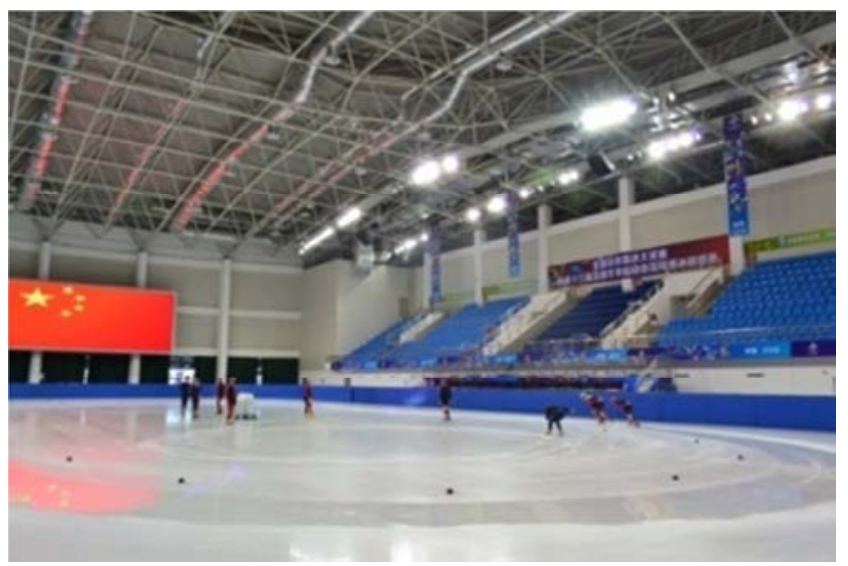

Figure 4. The curling hall, skating hall, and ice hockey hall.

\section{Conclusion}

This paper details the design of a mixture ratio for C40F250 concrete to meet demanding engineering specifications, both in terms of mechanical and working performance. The optimal ratio is determined on the basis of a comprehensive consideration of economy (Table 7, group no. "1"). Durability testing of this mix indicates that its low water-binder ratio can reduce the free moisture inside the concrete, thus reducing moisture evaporation in the concrete due to internal damage. It is also shown that incorporation of polypropylene synthetic fiber improves the anti-cracking performance of the concrete at the same time as, to a certain extent, reducing shrinkage. There is a particularly apparent reduction in the rate of early shrinkage. After 250 freeze-thaw cycles, the test block showed a mass loss at about $2 \%$ and a relative loss modulus at $88 \%$, meeting the relevant requirements.

This design was applied for C40F250 concrete underlying large confined ice layers in the venues of the 13th National Winter Games, China, meeting the needs of the project, generating praise from domestic and foreign experts, and providing valuable guidance for related projects.

\section{Acknowledgements}

The authors offer their thanks to China West Construction Group Xinjiang Co., Ltd for providing experimental support.

\section{References}

[1] Zhang Xu. The practical application of compensated shrinkage concrete in a project (in Chinese) [J]. Henan building materials, vol 02, pp. 159-161, 2015.

[2] Xu Shu-guo, Zhu Yu. Application of Laser Leveling Machine to Large Wear-resisting Floor Construction (in Chinese) $[\mathrm{J}]$. Engineering construction and design, vol 05, pp. 139-141+145, 2018.

[3] Fan Shu-jing, Wang Pei-ming. Drying Shrinkage and Cracking Behavior of Polypropylene Fiber Reinforced Glazed Hollow Beads Thermal Insulation Mortar (in Chinese) [J]. Journal of building materials, vol 01, pp. 118-123, 2017. 
[4] Chen Xin, Zheng Jian-lan, Wang Guo-jie. Influence of mineral admixture on the drying shrinkage performance of recycled concrete (in Chinese) [J]. Concrete, vol 10, pp. 16-20+24, 2016.

[5] Xu Yong-kun, Yao Ji-yong, Xie Yong-pei Etc. Application of Shrinkage-Compensating Concrete in Winter Construction of Basement (in Chinese) [J]. Expansive agent and expansive concrete, vol 02, pp. 17-21, 2015.

[6] Sun Jun-feng. Application of shallow draft gas in antifreeze concrete (in Chinese) [J]. Technical Supervision in Water Resources, vol 25, pp. 59-60+67, 2017.

[7] Ren Wei-ji. Design and engineering application of large volume compensated shrinkage concrete mix ratio in winter application (in Chinese) [J]. Float subsequently, vol 08, pp. 71-73, 2015.

[8] Li Chang-cheng, Zhang Ming, Huang Sheng. Preparation and engineering application of $\mathrm{C} 35 \sim \mathrm{C} 40$ shrinkage compensating concrete (in Chinese) [J]. Concrete, vol 10, pp. 160-162, 2017.

[9] JGJ 55-2011, Specification for design of ordinary concrete mix proportion (in Chinese) [S]
[10] GB/T 50080-2002, Standard test method for performance of ordinary concrete mixtures (in Chinese) [S].

[11] GB/T 50081-2002, Standard test method for mechanical properties of ordinary concrete (in Chinese) [S].

[12] GB/T 50082-2009, Standard test method for long - term performance and durability of ordinary concrete (in Chinese) [S].

[13] Jia Li-li, Gao Yu-xin, Peng Yuan Etc. Analysis and Comparison of Different Testing Methods with Different Free Expansion Ratios for Expansive Concrete (in Chinese) [J]. construction technique, vol 45, pp. 27-29+33, 2016.

[14] Wang Jun-zeng, Cui Wen-sheng, Qin Lei. Real-time monitoring of early cracks in mass concrete (in Chinese) [J]. construction technology, vol 46, pp. 205-207, 2015.

[15] Fan Le-tao. Study on early cracking grading control system of premixed concrete (in Chinese) [D]. Lanzhou University Of Technology, 2017. 